\title{
浅析农村生态环境监测工作开展
}

\author{
周卉 \\ 聊城市茌平区环境监控中心 \\ DOI:10.32629/eep.v3i7.891
}

\begin{abstract}
[摘 要] 近些年,社会经济持续发展的情况下我国农村生态环境受到了严重的破坏,这种破坏对于人们 正常的生活产生了负面影响。为了能够保障生态环境,采取有效的环境监测成为了其中不可或缺的一环, 环境监测可以让人们更加准确了解当地的自然生态环境与自然环境产生的变化, 同时按照这一变化需 要采取与其需求相对的保护措施, 为实现良好的保护效果创造发展基础。农村环境监测工作当前已经开 局,采取空气、地表水、饮用水源以及土壤等环境要素的收集和采样措施已经成为了农村生态环境监测 工作的首选, 同时在选择过程中还需要不断的另其得到完善, 并且要让这套措施与我国农村村庄实际特 点保持一致,这些基础工作是当前最为迫切的。此外,评价方法与评价标准存在的空白也是当前需要被有 效填补的领域,这就要求相关监测人员积极持续的完成探讨同时将其付诸于实践。
\end{abstract}

[关键词] 农村生态环境; 环境监测; 环境保护

中图分类号: Q142.6 文献标识码：A

\section{1 农村生态环境监测的意义}

农村生态环境监测应在依法治理环 境, 建设好农村环境监督和监测队伍的 前提下, 完成对农村资源的合理利用及 开发保护, 维护生态平衡, 不但让人类的 身体保持健康, 同时还极大程度的对完 善了城市的环境、经济、生态等多方面 的效益 ${ }^{[1]}$ 。

\section{2 农村生态环境监测的内容}

\section{1 例行监测}

例行监测是县监测站在环境监测 工作中的主体, 不但能够为环境容量的 认知提供有效依据, 同时还能够非常好 的积累多种历史资料, 对日后发展趋势 给予精准的预测提供了切实可行的方 法。当前, 我们要求将探索的核心摆在 怎么样强化提升例行监测数据资料能够 保持不间断, 同时确认监测获得的数据 能够更加的精准, 监测点获取的数据是 否具有代表性等多个问题上。

\section{2 特种目的监测}

其与特种目的监测相同, 无论是在 内容或是形式以及目的上都比较相近。 诸如对于污染事故仲裁监测和污染源的 调查监测以及企业升级监测等。

2.3 研究性监测
污染物的确认以及探明的监测, 其 主要是参照某一生态环境课题作为研究 目的, 测试主要是从排放源至受体的整 体过程, 同时对于这一过程里污染物自 身的浓度和污染物对于环境产生的负面 影响。环境监测是间断或连续地测定环 境中污染物的浓度, 观察、分析其变化和 对环境影响的过程 ${ }^{[2]}$ 。因此环境检测特 种目的通常是为接受任务, 现场调查和 收集资料, 监测计划设计, 优化布点, 样 品采集, 样品运输和保存, 样品的预处理, 分析测试, 数据处理, 综合评价等。环境 监测的对象: 自然因素, 人为因素, 污染 组分。环境监测包括: 化学监测, 物理监. 测, 生物监测, 生态监测。

\section{3 农村生态环境质量监测的布} 点原则

农村环境质量涉及到的内容主要包 含: 农村水环境和空气环境以及土壤环 境质量等多个方面的内容, 指的是农村 当前人居环境质量以及农业生产相互关 联的环境质量。当前我国农村的数量仍 然较多, 村落的数量与面积也是广阔无 垠的, 我们并没有条件去一个一个的对 于村庄环境质量完成监测采样, 但是我 们能够在对于农村环境情况的基础信息
有一个大体了解的基础上, 对于我国几 种基础类型村庄的分布以及组成情况去 完成分析统计, 在监测的基础上, 能够使 用何种地区的何种类型的一种比较有指 向性和代表性的村庄 ${ }^{[3]}$ 。在对典型村庄 进行选择上选择, 环境质量监测所进行 的布点需要按照以下原则去完成:

3. 1 优选点位, 注重代表性

保障农村环境质量监测和结论保持 科学和客观以及真实的核心是: 在对于 选点进行定位和优选前, 需要对其所需 要进行调查农村实际的污染源和环境情 况等有一个较为详细的调查与了解, 使 得被调查村庄能够具备一定的代表性并 且进行监测的结果可以更为精准并且真 实得展现出当前农村环境质量监测的有 效点位。

3. 2 随机布点, 突出重点的原则

对监测点位依照随机性的原则去完 成布设, 针对地区不同的农村环境质量 给予有效的监测, 这样才可以比较客观 并且较为全面的展现出农村环境质量的 实际情况。对于那部分已经被证实或者 是保持一种怀疑态度的污染相对较为严 重的地域, 需要事先考量的是布设, 并按 照具体的情况适当的增加监测点位, 强 
化对这一地区环境质量情况的监测与掌 握 $^{[4]}$ 。

\section{4 监测项目的确定原则}

我们需要对于当前农村是的环境质 量给予有效的监测, 就要求挑选适当的 监测项目, 同时选择的这样一个项目还 一定要具备代表性和灵活性, 以及针对 性与可操作性等多种特点。换言之, 我们 当前选择的选环境指标并不是随意设定 的, 其环境指标的设定是十分严苛的, 它 不仅需要具备一定的代表性, 同时还要 求能够反映出当前农民实际的生产生活 以及身体健康等情况, 除此之外, 还需要 对于环境在动植物生长上的影响程度给 予考量。我们当前选择的监测项目也并 不是毫无根据的, 它一定要将对农村的 环境质量监测作为参照, 一定要像镜子 一样, 不但可以展现出农产品当前所处 在的地理环境质量, 同时还要求能够展 现出农村当前的环境情况。但是其中不 能够忽略的一点是, 农村当前的条件并 不是十分的理想, 交通也并不是十分的 便捷、水电供应状况也较为糟糕, 这就为 农村环境监测带去了非常严峻的挑战, 不仅仅需要剧本能够便于监测的相关评 价指标, 同时还要求其能够具备强大操 作性的一个监测指标。

\section{5 农村生态环境监测应做到四} 个结合

5. 1 常规监测和重点监测保持结合

针对当前情况分析,农村环境监测 工作仍然有很多不足, 农村环境监测工
作还是一个新的课题, 其并未完全的进 入到成熟期, 监测内容也并未得到确认、 监测指标定位并不明晰、监测频率存在 高低不一致的情况, 这部分缺陷让监测 工作与常态化发展目标仍然存在较大的 差异, 也正是这样, 农村环境监测工作显 得十分迫切, 尤其是涉及到了农民群众 生产生活以及经济社会发展的核心环节, 更是需要对其给予严格监测。比如, 化肥 农药产生的农业污染和规模化养殖产生 的疫病危险等。

5.2 被动监测与主动监测相结合

当前农村环境监测工作的进行仍然 缺乏人们的高度关注, 负责进行监测的 部门对于当前农村环境存在的问题仍然 是保持一种视而不见的态度, 所以, 当前 的农村环境监测工作仍然是被忽略的。 可是, 农村经济社会发展对于环境监测 工作也提出了一些新的要求, 监测工作 一定要从被动型朝着主动型发展, 并且 需要与农民群众的呼声保持一致, 让环 境问题获得有效的监督与控制 ${ }^{[5]}$ 。

5. 3独立监测与联合监测相结合

目前, 农村环境监测工作进行负责 的部门仍然是环保和农业等部门, 它们 并未将对环境的有效监测作为出发点, 部门之间 “各自为政” 的情况仍然存在, 监测成果相对快发并且信息发布的并不 是十分及时、农民群众所能够进行诉求 的渠道相对狭窄。对于存在的这部分问 题, 我们需要清除的认识到与工作联合 的重要性, 不断提升监测力度, 拓展监测
层面, 完成资源的有效共享, 采取单独监 测与联合监测并驾齐驱的监测与管理方 式, 这是符合具体情况同时又是切实可 行的。

\section{6 结语}

农村经济在持续快速的发展, 随之 产生的是对于当前农村环境发展条件 以及发展因素的变化, 农民群众对其有 着比较深切的体会, 因此农民群众也是 最具有发言权的。基于这样的一种情况 下, 相关职能部门需要在农村环境监测 过程中充分的发挥出核心作用, 并且还 需要农民群众之间保持紧密的配合, 可 以说这是当前监测工作进行的一个理 想状态, 同时也是需要积极努力的发展 方向。

\section{[参考文献]}

[1]黄鹏.浅谈监理工程师的环境工程 监理工作[J].四川环境,2006,(1):108-110.

[2]张华云, 李强.工业企业发展循 环经济应注意的几个问题 [J]. 环境管 理,2016,(7)18-20

[3]刘文清,杨靖文,桂华侨,等. “互联网 +”智慧环保生态环境多元感知体系发展研 究[J].中国工程科学,2018,20(2):111-119.

[4]李国庆,陈鹏飞.环境监测技术的 应用现状及发展趋势[J].城市建设理论 研究(电子版),2016,(35):78-79.

[5]杨颖,洪沁.浅论生态环境监测 的现状及发展趋势 [J]. 资源节约与环 保,2015,(10):84. 